\section{Nordion clarifies agreement with JSC Isotope of Russia}

In response to the CMAJ news article, "Uncertainties shroud medical isotope supply," we at Nordion would like to clarify the record with regard to the statement: Isotope supplier MDS Nordion has begun importing isotopes from Russia as part of broader, "multi-source" approach to isotope supply.

To state that Nordion is importing isotopes from Russia that would be available to the market is misleading. Nordion has not begun importing commercial quantities of isotopes from Russia, though it has received some samples for testing.

Nordion has an agreement with JSC Isotope of Russia, which continues to develop its processing capability and capacity of Mo-99. JSC Isotope has not fully ramped up supply, which we expect to occur before 2016. We estimate that JSC Isotope will be able to supply less than our current requirements.

In light of the quantities of Mo-99 forecasted, Nordion expects to continue to discuss with JSC Isotope our current contractual arrangements and, in addition to pursuing the completion of the MAPLE reactors through the ongoing arbitration proceedings, continue to assess potential alternate sources of long-term medical isotope supply.

These are very critical distinctions, both to Nordion and the medical community. We appreciate the opportunity to clarify.

\section{Tamra Benjamin MBA}

Vice-President, Public and Government Relations, Nordion Inc., Ottawa, Ont.

\section{Reference}

1. Lougheed T. Uncertainties shroud medical isotope supply. CMAJ 2012;184:E567-8.

CMAJ 2012. DOI:10.1503/cmaj.112-2084

\section{Splenectomy: reducing the risk of infection}

We agree with the recommendations made in the review by Petrescu and colleagues that outlines important issues surrounding vaccination and discusses the risks of overwhelming postsplenectomy infection in patients who are or will be asplenic following splenectomy. ${ }^{1}$ Surgical or traumatic removal of the spleen is an important and easily recognizable medical event that should prompt a discussion between physician and patient regarding the risk of overwhelming postsplenectomy infection.

Equally important, but not mentioned in the review, is the hyposplenic state associated with a number of common medical conditions. In addition to congenital hyposplenism (which is rare), splenic atrophy with functional asplenia is frequently present in sickle cell disease, celiac disease, advanced HIV infection, and in patients with chronic graft-versus-host disease following hematopoietic stem cell transplantation. A complete list of medical conditions has been published elsewhere. ${ }^{2}$

Medically hyposplenic patients are at a similar risk of overwhelming postsplenectomy infection as those with surgical asplenism, and all such patients should be counselled about the risk and offered the appropriate vaccinations as outlined by Petrescu and colleagues. ${ }^{1}$ Medical hyposplenism must be suspected by history of a relevant medical condition, and can be confirmed by the presence of characteristic findings on the peripheral blood smear, such as Howell-Jolly bodies, acanthocytes or nucleated red blood cells. Functional radionuclide (technetium-based) scans can provide quantification of splenic function, but are expensive and generally unnecessary. We urge clinicians to consider medically hyposplenic patients for vaccination and counselling regarding the risk of overwhelming postsplenectomy infection.

Terry Wuerz MD, Matt Seftel MD MPH The Department of Internal Medicine, Section of Infectious Diseases (Wuerz); and Section of Hematology and Oncology (Seftel), University of Manitoba, Winnipeg, Man.

\section{References}

1. Petrescu D, Gold WL, Leis JA. Reducing the risk of infection in a patient who will undergo splenectomy. CMAJ 2012;184:1053-4.

2. Di Sabatino A, Carsetti R, Corazza GR. Postsplenectomy and hyposplenic states. Lancet 2011; 378:86-97.

CMAJ 2012. DOI:10.1503/cmaj.112-2082

\section{The authors respond}

We thank Wuerz and Seftel for their comment. ${ }^{1}$ Our review ${ }^{2}$ did not address patients with functional asplenia, as it was designed specifically as a counselling scenario around the case of a patient contemplating elective splenectomy.

In our experience, the period before surgical splenectomy is often a missed opportunity for patient education and health promotion. We agree, however, that the management principles for surgically asplenic patients apply equally to patients with functional asplenia. ${ }^{3}$ Early recognition of these patients, as outlined by Wuerz and Seftel, ${ }^{1}$ is crucial to ensure that patients receive appropriate counselling, education about high-risk circumstances, immunizations and appropriate empiric antimicrobial therapy if they present with febrile illness, including overwhelming postsplenectomy infection.

Dan Petrescu MD, Wayne L. Gold MD, Jerome A. Leis MD

The Department of Medicine (Petrescu), University of Toronto, and the Division of Infectious Diseases (Gold, Leis), University Health Network, Toronto, Ont.

\section{References}

1. Wuerz T, Seftel M. Splenectomy: reducing the risk of infection [letter]. CMAJ 2012;184:1926.

2. Petrescu D, Gold WL, Leis JA. Reducing the risk of infection in a patient who will undergo splenectomy. CMAJ 2012;184:1053-4.

3. Brigden ML. Detection, education and management of the asplenic or hyposplenic patient. $\mathrm{Am}$ Fam Physician 2001;63:499-508.

CMAJ 2012. DOI:10.1503/cmaj.112-2083

The CMAJ article by Petrescu and colleagues ${ }^{1}$ emphasized the critical interventions - particularly vaccination that can prevent life-threatening disease in an immunocompromised population. The authors note that vaccination against 